NBER WORKING PAPER SERIES

\title{
HOW TO PROTECT FUTURE GENERATIONS USING TAX BASE RESTRICTIONS
}

\author{
Antonio Rangel \\ Working Paper 9179 \\ http://www.nber.org/papers/w9179 \\ NATIONAL BUREAU OF ECONOMIC RESEARCH \\ 1050 Massachusetts Avenue \\ Cambridge, MA 02138 \\ September 2002
}

The author is indebted to John Conley for his extensive help in writing this paper. I would also like to thank Alan Auerbach, Doug Bernheim, Michael Boskin, Stephen Coate, Maxim Engers, Dennis Epple, Ed Glaeser, John Hat.eld, Chad Jones, Ken Judd, John Keenan, William Johnson, Jon Levin, Tom Nechyba, Klaus Nehring, Roger Noll, Wallace Oates, Luis Rayo, Robert Rosenthal, Emmanuel Saez, Rob Schwab, Steven She.rin, Holger Sieg, Joaquim Silvestre, Jonathan Skinner, Steve Tadelis, Michael Waldman, Barry Weingast, and seminar participants at Berkeley, Cornell, Duke, Hoover Institution, NBER, University of Maryland, University of Virginia, and UCLA for useful discussions and comments. The views expressed herein are those of the authors and not necessarily those of the National Bureau of Economic Research.

(C) 2002 by Antonio Rangel. All rights reserved. Short sections of text, not to exceed two paragraphs, may be quoted without explicit permission provided that full credit, including (C) notice, is given to the source. 
How to Protect Future Generations Using Tax Base Restrictions

Antonio Rangel

NBER Working Paper No. 9179

September 2002

JEL No. H0, H2, H3, H4, H5, H6, H7

\begin{abstract}
$\underline{\text { ABSTRACT }}$
This paper studies constitutional restrictions on the tax base that protect future generations from expropriation and improve the optimality of investment in Intergenerational Public Goods (IPGs). The choice of the tax base matters because it affects how intergenerational (IG) spillovers are capitalized into assets that are owned by current generations, and thus the IG politics. We show that with an income tax base, present generations expropriate future generations and produce inefficiently low levels of IPGs. By contrast, with a land tax base, IG expropriation using debt is impossible, the level of investment in IPGs is higher and, for some types of IPGs, Pareto optimal.
\end{abstract}

\author{
Antonio Rangel \\ Department of Economics \\ Stanford University \\ Stanford, CA 94305 \\ and NBER \\ rangel@leland.stanford.edu
}




\section{Introduction}

In every society present generations choose how much to invest in Intergenerational Public Goods (IPGs), such as public capital and the environment, and how much debt to pass to future generations. This gives rise to a basic question in political economy: Which institutions best protect future generations from expropriation and generate optimal investment in IPGs? This institutional problem is challenging because future generations do not vote, and the evidence suggests that present generations are imperfectly altruistic. 1

Although the prospects for future generations appear grim at first sight, recent work (described in the next section) has shown that some institutions are capable of solving the problem through "intergenerational (IG) capitalization". Selfish present generations do not care directly about the IG spillovers. However, they do care about other variables that affect their well-being, such as the future price of the assets that they own, or the future value of their social security benefits. An institution that capitalizes the IG spillovers into one of these variables indirectly induces present generations to care about their descendants.

In this paper we study constitutional restrictions on the tax base that give present generations incentives to internalize IG spillovers. A tax base restriction limits the type of taxes that the government can use to raise revenue, but not the level of expenditures. Tax base restrictions are important because, as we show, they have a significant effect on how IG spillovers are capitalized into assets that are owned by current generations, and thus on IG politics.

This paper is, in essence, an exercise in comparative institutional analysis. We develop a stylized political economy model in which these issues arise, and compare the outcomes generated by two constitutional rules: (1) a restriction to an income tax base, and (2) a restriction to a land tax base. First we show how the tax base restrictions affect the extent to which IG spillovers are capitalized into land values. Then we show the effect that the capitalization properties have on IG politics.

Our results show that an appropriate choice of constitutional restrictions on the tax base profoundly affects IG exchange. With an income tax base, present generations expropriate future generations and produce inefficiently low levels of IPGs. By contrast, with a land tax base, IG expropriation using debt is impossible, the level of investment in IPGs is higher and, for some types of IPGs, Pareto optimal.

These results have implications for the design of tax systems. A constitution could protect future generations by requiring the use of a multi-tier tax system, which divides the government budget into several well-defined tiers, and puts hard constraints on the

\footnotetext{
${ }^{1}$ See, for example, the studies of Altonji, Hayashi and Kotlikoff $(1992,1997)$.
} 
tax base that can be used to finance the expenditures in each category. The system would have at least two tiers: (1) an intergenerational tier containing the debt and programs that generate IG spillovers; and (2) an intragenerational tier containing all other programs, including redistribution and corrective taxation. Our results suggest that the IG tier should be financed exclusively with land type taxes, but do not impose any constraints on the tax base for the second tier.

The rest of the paper is organized as follows. Section 2 discusses the related literature. Section 3 describes the basic model. Section 4 compares the outcomes generated by an income and a land tax base. Section 5 introduces some practical concerns. Section 6 concludes by discussing the practical implications of our results for the design of tax systems. The proofs are in the appendix.

\section{Related Literature}

This paper is related to several literatures. First, Poterba (1994), Bohn and Inman (1995), Alt and Lowry (1994), and Kiewiet and Szakaly (1996) study budgetary institutions such as capital accounts. ${ }^{2}$ The goal of these institutions is also to protect future generations, but they work through a different mechanism. Instead of relying on "IG capitalization", they restrict the government's ability to issue debt. For example, some institutions restrict the use of debt to the financing of concrete capital projects that have to be approved in a special referendum.

Second, Rangel (2002) and Boldrin and Montes (1998) study investment in IPGs in economies without durable assets. They show that majority rule institutions generate equilibria in which "political capitalization" takes place: present selfish generations vote to invest in IPGs because otherwise future voters will cut their social security benefits. Unlike the land market capitalization studied here, "political capitalization" is sustained by cooperative equilibria in infinitely repeated games, and, as a result, there are always bad equilibria in which investment in IPGs does not take place. By contrast, we show that a restriction to a land tax base always generates a positive level of investment in IPGs.

Third, Oates and Schwab (1988,1996), Glaeser (1996), Kotlikoff and Rosenthal (1993), Rangel and Conley (2002), and McKinnon and Nechyba (1997) also study how to protect future generations by inducing the capitalization of IG spillovers into land values. The difference with our paper is the mechanism at work. Here we look at centralized institutions in which the IG spillovers affect land prices solely through their effect on the taxes of future generations. By contrast, this literature looks at decentralized institutions where interjurisdictional competition provides the capitalization

\footnotetext{
${ }^{2}$ See also the Report of the President's Commission on Capital Budgeting (1999).
} 
force: future voters prefer jurisdictions with less debt and more IPGs and thus bid up the price of land in those jurisdictions. Finding a way to protect future generations without relying in federalism is important because some IPGs, such as R\&D or military capital, cannot be decentralized, and historically central governments have issued large amounts of debt.

Fourth, the paper is also related to the literature on the incidence of taxation, which takes tax changes as exogenously given, and studies the burden that they generate. ${ }^{3}$ For example, Feldstein (1977) shows that the introduction of a land tax immediately capitalizes all future taxes into land prices. By contrast, here we study how the (known) incidence properties of different tax bases affect the politics of IG redistribution and investment.

Finally, like the famous Henry George Theorem (see Atkinson and Stiglitz, ch. 17), this paper shows that a restriction to a land tax base has attractive properties. However, the relationship between the results stops there. Here the land tax base is attractive because of its political economy properties. By contrast, the Henry George Theorem shows that in static economies, under some special conditions, the equilibrium land values equal the cost of providing the optimal level of the public good.

\section{Basic Model}

\subsection{Economy}

Consider an economy with two periods, $t=1,2$, and two homogeneous generations, $\alpha$ and $\beta$. Each generation is of size $N$. There are three goods: a private numeraire good, land, and an intergenerational public good (IPG). ${ }^{4}$

The timing of events is summarized in Figure 1. Generation $\alpha$ is alive in period 1. Each member receives an endowment of $\frac{L}{N}$ units of land and $w$ units of the private good. Generation $\beta$ is born between periods 1 and 2. Each member is endowed with $w$ units of the private good but no land. At the beginning of period 2 there is a land market in which generation $\beta$ buys the land from generation $\alpha$. At this point generation $\alpha$ consumes its wealth, exits the economy, and dies.

The preferences of generation $\alpha$ are equal to their life-time wealth. ${ }^{5}$ The preferences of generation $\beta$ are given by $u(c)+v(l)+h(G)$, where $c, l$ and $h$ denote, respectively, the consumption of the private good, land, and IPG. $u(\cdot), v(\cdot)$, and $h(\cdot)$ are twice continuously differentiable, strictly concave, and satisfy the Inada conditions.

\footnotetext{
${ }^{3}$ See Auerbach and Hines (2002) and Kotlikoff and Summers (1997) for summaries of this literature.

${ }^{4}$ The results in this paper also hold in models with an infinite number of generations. The two period model used here, however, provides a better environment to understand the forces at work.

${ }^{5}$ This assumption is made just to simplify the exposition. If agents can borrow and save, this is equivalent to assuming that generation $\alpha$ maximizes a utility function $U\left(c^{1}, c^{2}, l\right)$.
} 
Let $p$ denote the price of land, and

$$
\lambda(p \mid x) \equiv \underset{l \geq 0}{\arg \max } u(x-p l)+v(l)
$$

denote the demand for land of a member of generation $\beta$ who has wealth $x$. The following properties, proven in the appendix, will be used repeatedly in the analysis.

Property 1: For all $x>0$ there exists a unique land price $\pi(x)$ for which $\lambda(\pi(x) \mid x)=$ $\frac{L}{N}$.

Property 2: $\frac{L}{N} \frac{\partial \pi(x)}{\partial x} \in(0,1)$.

Property 3: $\frac{\partial \pi(x)}{\partial x} \rightarrow 0$ as $\lambda_{x} \rightarrow 0 .{ }^{6}$

Since agents are homogenous, in equilibrium they must purchase $\frac{L}{N}$ units of land. Property 1 says that, for any for any level of after tax wealth $x$, there is a unique land price that clears the market. Property 2 follows from the fact that, since under our assumptions all goods are normal, agents only spend a fraction of each extra unit of wealth on land. Finally, Property 3 says that land prices do not change with income when the demand for land is sufficiently income inelastic.

Figure 1 also describes the timing of political choices. At time $t=1$ there is an election in which generation $\alpha$ makes two decisions: how much debt to issue, denoted by $D$, and how much to invest in the IPG, denoted by $I$. At the end of $t=2$ there is an election in which generation $\beta$ chooses additional expenditures on the IPG, denoted by $E$. Negative levels of $D$ represent public savings. Generation $\beta$ always honors the debt. The gross interest rate is exogenously given and equal to 1.

The production function for the IPG is given by

$$
G=\theta I+E
$$

We assume that $\theta>1$ so that it is optimal to invest in the IPG at $t=1$. If this were not the case, the IPG would become a regular public good, and the IG incentive problem would disappear. $\theta-1$ measures the strength of the IG spillovers.

In the basic model we assume that the IPG is non-reversible: $E \geq 0$. Examples of this type of IPG include the environment and investments in public infrastructure. In section 4.3 we provide straightforward extensions to reversible IPGs $(E \geq-\theta I)$ and to pure IPGs $(E=0)$.

The reader may wonder why we do not develop the basic results for the seemingly simpler case of pure IPGs. There are two reasons. First, that case misses an essential property of most of IPGs, which is that future generations can provide the public

\footnotetext{
${ }^{6} \lambda_{p}$ and $\lambda_{x}$ denote, respectively, the derivative of the land demand function with respect to price and wealth.
} 
good, albeit at a higher cost, if present generations do not do so. For example, the need for future environmental expenditures depends on the amount of damage done in the present. Second, as we show below, pure IPGs are a knife-edge case.

\subsection{Institutions}

Political decisions are made by majority rule voting over the set of feasible policies, or by any other institution, such as Downsian competition, that selects Condorcet winners as the unique equilibrium outcomes whenever they exist. Since agents are homogenous, the existence of a Condorcet winner is trivially guaranteed: it is equal to the preferred policy of the representative voter. The politics become more complex in section 5 where we extend the results to the case of heterogenous agents.

We consider two institutions which only differ on the type of tax base restriction imposed on the government: a restriction to an income tax base and a restriction to a land tax base. The first institution is denoted by $I$, the second by $L{ }^{7}$

With an income tax base, all taxes, positive and negative, are collected using income taxes. Given that agents are homogenous, without loss of generality we can model the income tax as a lump-sum tax. ${ }^{8}$ Thus, the income taxes in periods 1 and 2 , as a function of the policy choices, are given by

$$
T_{1}(I, D)=\frac{I-D}{N} \text { and } T_{2}(E, D)=\frac{E+D}{N} .
$$

Note that the debt reduces the taxes of generation $\alpha$ and increases the taxes of generation $\beta$.

With an income tax base, all taxes, positive and negative, are collected using a tax per-unit of land. ${ }^{9}$ The land taxes in periods 1 and 2 , as a function of the policy choices, are given by

$$
\tau_{1}(I, D)=\frac{I-D}{L} \text { and } \tau_{2}(E, D)=\frac{E+D}{L}
$$

Finally, to simplify the exposition we also assume that there is a debt-ceiling $D_{\max }$. The role of this constraint is further explained below.

\footnotetext{
${ }^{7}$ Tax base restrictions come in different degrees of completeness. At one extreme, a complete tax base specifies a detailed mapping from government expenditures to the taxes paid by each individual as a function of his behavior. At the other extreme, an incomplete tax base specifies that certain types of taxes cannot be used, but does not pin down the level of the taxes that are allowed. In this paper we study the political economy properties of complete tax bases.

${ }^{8}$ In section 5 we extend the analysis to the case of heterogenous agents and consider more general income taxes.

${ }^{9}$ Previous studies (e.g., Skinner (1991)) have emphasized the difficulties of administering a land tax. These studies, however, have considered land-taxes based on market values, which are difficult to measure and monitor, instead of taxes per-unit of land.
} 


\subsection{Equilibrium}

To characterize the outcomes generated by the two institutions we need to define the following objects for $(k=I, L): s \equiv(\theta I, D)$ is a state variable summarizing the level of IPG $s_{1}=\theta I$ and the level of debt received from the first generation; $p^{k}(s)$ is a capitalization function describing the equilibrium price of land; $E^{k}(s)$ is a policy response function describing the expenditures in IPGs at time $2 ; G^{k}(s) \equiv \theta I+E^{k}(s)$ is the level of the IPG consumed by generation $\beta ; c^{k}(s)$ is the amount of private good consumed by generation $\beta ;\left(I^{k}, D^{k}\right)$ is the outcome of the election at time 1 ; and, finally, $G^{k} \equiv \theta I^{k}+E^{k}\left(\theta I^{k}, D^{k}\right)$ is the equilibrium level of the IPG.

DEF 1: An equilibrium for $I$ is given by $\left(p^{I}(\cdot), E_{2}^{I}(\cdot), I^{I}, D^{I}\right)$ satisfying:

(i) Political equilibrium in period 2: for all $s$

$$
E^{I}(s)=\underset{E \geq 0}{\arg \max }\left[u\left(w-p^{I}(s) \frac{L}{N}-T_{2}(E, D)\right)+h(\theta I+E)\right]
$$

(ii) Land market equilibrium: for all $s, p^{I}(s)$ satisfies

$$
\frac{L}{N}=\lambda\left(p^{I}(s) \mid w-T_{2}\left(E^{I}(s), D\right)\right)
$$

(iii) Political equilibrium in period 1:

$$
\left(I^{I}, D^{I}\right) \in \underset{I \geq 0, D \leq D_{\max }, I \leq N w+D}{\arg \max }\left[p^{I}(\theta I, D) \frac{L}{N}-T_{1}(I, D)\right] .
$$

DEF 2: An equilibrium for $L$ is given by $\left(p^{L}(\cdot), E^{L}(\cdot), I^{L}, D^{L}\right)$ satisfying:

(i) Political equilibrium in period 2: for all $s$

$$
E^{L}(s)=\underset{E \geq 0}{\arg \max }\left[u\left(w-\left(p^{L}(s)+\tau_{2}(E, D)\right) \frac{L}{N}\right)+h(\theta I+E)\right]
$$

(ii) Land market equilibrium: for all $s, p^{L}(s)$ satisfies

$$
\frac{L}{N}=\lambda\left(p^{L}(s)+\tau_{2}\left(E^{L}(s), D\right) \mid w\right)
$$

(iii) Political equilibrium in period 1:

$$
(I, D) \in \underset{I \geq 0, D \leq D \max , I \leq N w+D}{\arg \max }\left[\left(p^{L}(\theta I, D)-\tau_{1}(I, D)\right) \frac{L}{N}\right]
$$

Note a few important features of these definitions. First, the institutions only differ on how policy choices map into taxes. In $L$ the amount of taxes paid by each agent depends on his market choices. In particular, land taxes affect the total cost of owning land but not the wealth of the agents (see (9)). By contrast, in $I$ taxes are independent of market choices and affect after tax wealth (see (6)). 
Second, the outcome of the election is given by the representative agent maximization problems described in (5), (7), (8) and (10). Furthermore, since $\tau_{k}(\cdot) \frac{L}{N}=T_{k}(\cdot)$, the change in the tax base has no effect on how taxes are shared in equilibrium: each agent pays $\frac{1}{N}$ th of the taxes in both cases. Thus, any differences between $I$ and $L$ must be due to their capitalization properties.

Third, since agents are identical, in equilibrium they consume an identical amount of land. As described in (6) and (9), the land price adjusts in every state to get agents to demand $\frac{L}{N}$ units of land.

Fourth, agents have rational expectations. This assumption plays a crucial role in the results. When generation $\alpha$ votes at time 1, it anticipates the consequences of its decisions on land prices (see (7) and (10)). When the members of generation $\beta$ decide how much land to buy, they anticipate the taxes that they will be pay later in the period (see (6) and (9)).

Fifth, agents are price takers and policy takers. In particular, when they choose how much land to buy, they take the future political outcomes as given. As in the case of the market, the justification is that with sufficiently large electorates agents do not believe that they can affect the outcome of the election.

\subsection{Tax vs. Benefit Spillovers}

To understand the results in this paper is important to keep in mind that the actions of generation $\alpha$ induce two types of effects on generation $\beta$ : tax and benefit spillovers.

Tax spillovers arise because the total taxes paid by generation $\beta, E^{k}(s)+D$, depend on the state of the world. In particular, each additional unit of debt increases future taxes by $1+\frac{\partial E^{k}(s)}{\partial D}$, and each additional unit of IPGs by $\frac{\partial E^{k}(s)}{\partial s_{1}}$.

Benefit spillovers arise because the actions of generation $\alpha$ affect the level of IPGs $G^{k}(s)$ consumed by generation $\beta$.

In both cases, the spillovers result from the combination of the actions of generation $\alpha$ and the reaction by generation $\beta$. Consider, for example, the effect of increasing the debt by one unit. In the absence of a behavioral response by generation $\beta$, this increases the budget at time 2 by one unit, but has no effect on the IPGs. Thus, it generates a positive tax spillover, but not a benefit spillover. However, as we show below, with an income tax base generation $\beta$ reacts by decreasing its expenditures in IPGs. This generates additional negative tax and benefit spillovers.

\section{Income vs. Land Taxation}

Before characterizing the outcomes generated by the two institutions, it is useful to look at their general capitalization properties. Suppose that, for exogenous reasons, 
the government at $t=2$ provides $G$ units of the IPG and has to raise $B$ units of taxes. This requires a lump-sum $\operatorname{tax} \frac{B}{N}$ with an income tax base, and a land tax $\frac{B}{L}$ with a land tax base. The following result characterizes the capitalization functions $p^{L}(G, B)$ and $p^{I}(G, B)$.

PROP 1: (i) Neither institution capitalizes benefit spillovers: $\frac{\partial p^{L}}{\partial G}=\frac{\partial p^{I}}{\partial G}=0$.

(ii) With a land tax base there is full capitalization of tax spillovers: $L \frac{\partial p^{L}}{\partial B}=-1$.

(iii) With an income tax base there is under-capitalization of tax spillovers: $L \frac{\partial p^{I}}{\partial B} \in(-1,0)$ and $\lim _{\lambda_{x} \rightarrow 0} \frac{\partial p^{I}}{\partial B}=0$.

The proof of this result is simple and provides an essential intuition. Consider, first, the case of a land tax base. The equilibrium price of land is determined by the land market clearing condition $\frac{L}{N}=\lambda\left(p^{L}(G, B)+\frac{B}{L} \mid w\right)$. By Property $1, p^{L}(G, B)+\frac{B}{L}=$ $\pi(w)$. It follows that $p^{L}(G, B)=\pi(w)-\frac{B}{L}$, benefit spillovers are not capitalized, and tax spillovers are fully capitalized.

Now consider the case of an income tax base. The equilibrium price of land is now determined by the land market clearing condition $\frac{L}{N}=\lambda\left(p^{I}(G, B) \mid w-\frac{B}{N}\right)$. Property 1 then implies that $p^{I}(G, B)=\pi\left(w-\frac{B}{N}\right)$. It follows that benefit spillovers are not capitalized. Furthermore, since

$$
L \frac{\partial p^{I}}{\partial B}=-\frac{L}{N} \frac{\partial \pi(x)}{\partial x}
$$

Properties 2 and 3 imply that $L \frac{\partial p^{I}}{\partial B} \in(-1,0)$ and goes to zero as $\lambda_{x} \rightarrow 0$. In the limit, when preferences are quasi-linear, $p^{I}(\cdot)$ is constant and there is no capitalization of either type of spillover.

This simple result has an important implication. In both institutions the choices of generation $\alpha$ affect land prices only through their effect on tax spillovers. If generation $\alpha$ leaves an extremely valuable IPG, but this has no impact on the taxes at $t=2$, the benefits are not capitalized!

The difference between the two institutions resides on how the tax spillovers affects land prices. With income taxation, an additional unit of tax spillovers increases prices because, when future generation are richer, they demand more land. However, since future generations also use the additional wealth to buy other goods, the capitalization effect is not a $100 \%$. For example, if agents spend $30 \%$ of their income in land, the capitalization effect is $30 \%$. By contrast, with land taxation the tax spillovers affect directly the total cost of owning land, but not wealth. In some sense, the income tax base operates through income effects, while the land tax channels the tax spillovers directly into price effects. 


\subsection{Income Tax Base}

The following result characterizes the equilibrium of the $I$ institution.

PROP 2: I generates a unique equilibrium with the following properties:

(i) The policy response at $t=2$ satisfies:

$$
\frac{\partial E^{I}}{\partial D} \in(-1,0) \text { and } \frac{\partial E^{I}}{\partial s_{1}} \in\left\{\begin{array}{cl}
(-1,0) & \text { if } s_{1}<\bar{G}^{I}(D) \\
\{0\} & \text { if } s_{1}>\bar{G}^{I}(D)
\end{array}\right.
$$

for some some decreasing function $\bar{G}^{I}(D)$.

(ii) The capitalization function satisfies:

$$
L \frac{\partial p^{I}}{\partial D} \in(-1,0) \text { and } L \frac{\partial p^{I}}{\partial s_{1}} \in\left\{\begin{array}{cl}
(0,1) & \text { if } s_{1}<\bar{G}^{I}(D) \\
\{0\} & \text { if } s_{\mathbf{1}}>\bar{G}^{I}(D)
\end{array} .\right.
$$

(iii) There is maximal IG expropriation: $D^{I}=D_{\max }$.

(iv) There is underinvestment in future generations: $I^{I}=0$ unless $\theta$ and $\lambda_{x}$ are sufficiently large.

(v) $G^{I}$ is Pareto inefficiently low.

We provide the intuition for this result in two steps. First we discuss what drives the capitalization of the spillovers. Then we discuss the impact that the capitalization function has on generation $\alpha$ 's incentives.

Consider, first, the properties of the capitalization function. As we have seen before only tax spillovers are capitalized. Thus, to understand how IPGs and debt are capitalized, we need to understand how they affect the government budget $B(s) \equiv E^{I}(s)+D$ in period 2. By proposition 1 we know that

$$
L \frac{\partial p^{I}}{\partial D}=L \frac{\partial p^{I}}{\partial B} \frac{\partial B}{\partial D}=L \frac{\partial p^{I}}{\partial B}\left(1+\frac{\partial E^{I}}{\partial D}\right)
$$

and

$$
L \frac{\partial p^{I}}{\partial s_{1}}=L \frac{\partial p^{I}}{\partial B} \frac{\partial B}{\partial s_{1}}=L \frac{\partial p^{I}}{\partial B} \frac{\partial E^{I}}{\partial s_{1}}
$$

where $1+\frac{\partial E^{I}}{\partial D}$ and $\frac{\partial E^{I}}{\partial s_{1}}$ measure the magnitude of the tax spillovers. The results then follow easily from the properties of the policy response function $E^{I}(\cdot)$, depicted in figure 2 (bottom). Additional units of $s_{1}$ either decrease taxes by less than one unit, or have no effect on taxes. By proposition 1, it follows that land prices go down by less than one unit, or do not change. Similarly, since $\frac{\partial E^{I}}{\partial D} \in(-1,0)$, each additional unit of debt increases the taxes of the next generation, but by less than one unit since it also reduces the expenditures in IPGs. Again, by proposition 1, it follows that land prices go down, but by less than one unit. 
The intuition for why $E^{I}(\cdot)$ satisfies these properties is also simple. As long as $E^{I}(s)>0$, the government at time 2 is indifferent between receiving an additional unit of IPGs or an additional unit of private goods. Both decrease the amount of taxes that the government needs to raise to provide a given level of IPGs by exactly one unit. Furthermore, since the tax spillovers are not fully capitalized, the additional unit of IPGs makes generation $\beta$ richer and thus it increases its demand of IPGs. However, since all of the goods are normal, the demand for IPGs goes up by less than the full unit. As a result, expenditures in IPG go down but by less than the full unit. Furthermore, as shown in figure 2, this implies that for high enough levels of IPGs, $E^{I}(s)=0$. At this point additional units of IPGs generate benefit spillovers, but not tax spillovers. A similar logic shows why $E^{I}$ decreases with $D$ but less than one-to-one.

Now consider how these properties of the capitalization function affect the incentives of generation $\alpha$. Each additional unit of debt decreases its tax bill by one unit but decreases land values by less than one unit. Thus, it pays to expropriate and so $D^{I}=D_{\max }$. Now consider their incentives to invest in IPGs, shown in figure 2 (top). Generation $\alpha$ has an incentive to increase $s_{1}$ only if this increases land prices by a sufficiently large amount. Thus, by Proposition 1, it invests only as long as $s_{1}$ generates a tax spillovers and if the capitalization effects are strong enough. Thus, it invests up to $\bar{G}^{I}\left(D_{\max }\right)$ when $L \frac{\partial p^{I}}{\partial s_{1}} \geq \frac{1}{\theta}$, and nothing if $L \frac{\partial p^{I}}{\partial s_{1}}<\frac{1}{\theta}$. Figure 2 depicts the later case. By Proposition 1, we can conclude that generation $\alpha$ invests in IPGs only if $\theta$ and $\lambda_{x}$ are large enough.

Note the role that the debt ceiling plays in this institution. As long as $D_{\max }+$ $E^{I}(s)<N w$, generation $\beta$ always has enough resources to pay off the debt, and also to invest in the IPGs when none are provided by the first generation. Given this, land prices are strictly positive in every state. The results also go through without the imposition of a debt-ceiling, but the analysis is more cumbersome. ${ }^{10}$

Summarizing, although $I$ is able to capitalize some tax spillovers, the magnitude of the effect is not sufficient to stop expropriation through the debt, or, in many cases, to induce present generations to invest in IPGs. This motivates the central question of this paper: can a change in the tax base improve outcomes?

\subsection{Land Tax Base}

The following result characterizes the equilibria of the $L$ institution.

PROP 3: L generates multiple equilibria (but a unique equilibrium allocation) given by:

\footnotetext{
${ }^{10}$ Since financial markets would never lend an amount that exceeds the tax base of future governments, without a debt ceiling it is necessary to keep track of the maximum amount of debt that generation $\beta$ could repay in every state.
} 
(i) $E^{L}(s)=\max \left\{\bar{G}^{L}-\theta I, 0\right\}$ with $\bar{G}^{L}>0$.

(ii) $L p^{L}(s)=L \pi(w)-\left(E^{L}(s)+D\right)$.

(iii) Any level of debt is an equilibrium, but it generates no IG redistribution.

(iv) All investment in IPGs is done by generation $\alpha: I^{L}=\frac{\bar{G}^{L}}{\theta}$

(v) $G^{L} \geq G^{I}$, with strict inequality if $\theta$ or $\lambda_{x}$ are sufficiently small or $D_{\max }>0$.

(vi) $G^{L}$ is Pareto inefficiently low.

As before, we provide the intuition for the results in two steps.

Consider, first, the properties of the capitalization function. As we have seen, a key feature of this institution is that IG spillovers affect the total cost of owning land, but have no effect on wealth. It follows that the price of land is given by

$$
L p^{L}(s)=L \pi(w)-\left(D+E^{L}(s)\right)
$$

i.e., tax spillovers are fully capitalized. Then, by the properties of $E^{L}(\cdot)$, depicted in Figure 3 (bottom) it follows that

$$
L \frac{\partial p^{L}}{\partial D}=-1 \text { and } L \frac{\partial p^{L}}{\partial s_{1}}=\left\{\begin{array}{ll}
1 & \text { if } s_{1}<\bar{G}^{L} \\
0 & \text { otherwise }
\end{array} .\right.
$$

Note that, in contrast to $I$, the income elasticity of land demand plays no role in the result.

With a land tax, generation's $\beta$ demand for IPGs is unaffected by $s_{1}$ or $D$. This is a direct result of full capitalization. Each additional unit of IPGs makes generation $\beta$ richer by reducing the amount of taxes that the government needs to collect, but it also makes it poorer by increasing the cost of land. The two effects cancel each other out. As a result, see figure 3 (bottom), each additional unit of IPGs reduces $E^{L}$ by exactly one unit. Once more, this implies that $E^{L}(s)=0$ for high enough levels of $s_{1}$. A similar logic shows that $E^{L}$ is not affected by the debt.

Now consider the impact of the capitalization effects on the incentives of generation $\alpha$. With full capitalization IG redistribution is impossible since the tax spillover of increasing the debt is exactly offset by the decrease on land values. As a result, the after tax wealth of generations $\alpha$ and $\beta$ is independent of $D$, and any feasible level of debt can be an equilibrium. Next consider the incentives to invest in IPGs, which are depicted in figure 3 (top). As before, generation $\alpha$ does not produce beyond $\bar{G}^{L}$ since only tax spillovers are capitalized. However, since the tax spillovers are fully capitalized, generation $\alpha$ makes a profit of $1-\frac{1}{\theta}$ on every unit of investment up to $\bar{G}^{L}$. Thus, for all $\theta>1$, all of the expenditures in IPGs are made by generation $\alpha$. This falls short of full efficiency, but at least is "constrained efficient" in the sense that the most efficient production technology is used. 
Figures 3 (top) can also be used to see why the equilibrium is Pareto inefficient. With $\theta>1$ efficiency requires that all IPGs be produced in the first period. At an interior Pareto optimal allocation the level of investment in future generations is such that $M S B(s)=M S C(s)$, where $M S C(s)=\frac{1}{\theta}$ measures the marginal social cost of investing in IPGs, and

$$
\operatorname{MSB}(s)=\left\{\begin{array}{cl}
1 & \text { if } s_{1}<\bar{G}^{L} \\
N \frac{h^{\prime}\left(s_{1}\right)}{u^{\prime}\left(c^{L}(s)\right)} & \text { otherwise }
\end{array},\right.
$$

measures the marginal social benefit, which is equal to generation $\beta$ 's aggregate willingness to pay for an additional unit of $s_{1}$. For $s_{1}<\bar{G}^{L}$, the MSB equals one since, as long as $E^{L}(s)>0$, additional units of IPGs are valuable only to the extent that they decrease the tax cost of consuming a given level of IPGs.

As the figure shows, generation $\alpha$ invests optimally only if it is sufficiently compensated for every unit of investment up to $G^{*}$. Generation $\beta$ would like to commit to compensate generation $\alpha$ for the cost of producing the additional IPGs, but it cannot credibly commit to do so since, in the institutions studied in this paper, the only feasible compensations are those that arise as the result market forces, and these forces only capitalize tax spillovers.

It is important to emphasize that in this institution land prices can be negative even though the total cost of owning land remains fixed at $\pi(w)>0$. As we have seen, the price of land is given by

$$
p^{L}(\theta I, D)=\pi(w)-\frac{\left(\max \left\{\bar{G}^{L}-\theta I, 0\right\}+D\right)}{L} .
$$

This function takes is lowest value at $\left(0, D_{\max }\right)$. It follows that, even when debt is not allowed $\left(D_{\max }=0\right)$, land prices can be negative out of equilibrium whenever $\bar{G}^{L}>$ $L \pi(w)$. Along the equilibrium path, the lowest land price is given by $p^{L}\left(\bar{G}^{L}, D_{\max }\right)=$ $L \pi(w)-D_{\max }$, which is positive as long as $D_{\max }<L \pi(w) .{ }^{11}$

Negative prices are a natural feature of the land tax base. Agents agree to sell at negative prices because, otherwise, they would be responsible for the taxes associated with the land. ${ }^{12}$ In fact, as shown in (12), generation $\alpha$ always makes a profit by selling the land since the price exceeds the tax burden per unit of land by $\pi(w)$.

Summarizing, a move from an income to a land-tax base generates full capitalization of tax spillovers, which is sufficient to eliminate IG expropriation, and to always induce the first generation to carry out all of the investment in IPGs, as required by efficiency.

\footnotetext{
${ }^{11}$ Out of equilibrium negative prices arise only in a fraction of environments. For example, in the Cobb-Douglass preferences of the form $A \log c+B \log l+C \log G$, one can show that $L \pi(w)>\bar{G}^{L}$ as long as $B>C$. When this condition is satisfied, there is a debt-ceiling $D_{\max }>\mathbf{0}$ which guarantees positive prices in and out of equilibrium. In general, negative prices arise when generation $\beta$ 's taste for the IPG is sufficiently stronger than its taste for land.

${ }^{12}$ We assume that land taxes are collected after the land market just before generation $\alpha$ dies.
} 


\subsection{Other Types of IPGs}

Now that we have developed a basic understanding of how the two institutions work we can easily extend the results to other types of IPGs.

Consider first the case of reversible IPGs, where $E(s) \geq-\theta I$, and future generations can decide to de-invest part of the stock that is bequeathed to them. For example, they could decide to sell excess government buildings or national parks. The model is exactly as before with one exception: the constraint for generation $\beta$ 's maximization problem in (5) and (8) becomes $E(s) \geq-\theta I$. This innocuous modification changes the nature of the IG spillovers: now an additional unit of IPGs always generates a tax spillover. Furthermore, since generation $\beta$ can always consume excessive levels of inherited IPGs, the mar ginal social benefit of an additional unit of IPGs is always equal to 1 .

Another important case are pure IPGs, where $E(s)=0$ for all $s$. Here, IPGs generate benefit spillovers, but not tax spillovers.

PROP 4: (i) In the case of reversible IPGs, $I^{L}$ is Pareto optimal, and $I^{I}$ is Pareto inefficiently low unless $\theta$ and $\lambda_{x}$ are sufficiently large.

(ii) In the case of pure IPGs, $I^{L}=I^{I}=0$.

The intuition for this proposition follows easily from our previous results. Since pure IPGs do not generate tax spillovers, they are not capitalized, and generation $\alpha$ has no incentive to produce them.

Now consider the case of reversible IPGs. Since each unit of IPGs costs $\frac{1}{\theta}$ units to produce, and generates 1 unit of private goods in period 2, optimality requires that the first generation invest it's entire endowment. Clearly, generation $\alpha$ has an incentive to do so only if $L \frac{\partial p}{\partial s_{1}} \geq \frac{1}{\theta}$ for all $s$. With a land tax base, each additional unit of IPGs generates one unit of tax spillovers, which is fully capitalized. Thus, $L \frac{\partial p^{L}}{\partial s_{1}}=1>\frac{1}{\theta}$. By contrast, with an income tax base each additional unit of IPGs generates less than one unit of tax spillovers, and that unit is capitalized by less than a hundred percent. As a result, $L \frac{\partial p^{I}}{\partial s_{1}}<\frac{1}{\theta}$ if $\theta$ or $\lambda_{x}$ are sufficiently small.

A comparison between irreversible, reversible, and pure IPGs provides additional intuition for the forces at work. Generation $\alpha$ only cares about the impact of its decisions on land prices. Thus, it internalizes the impact of its actions on the capitalization function, but not on the well-being of future generations, as described by the $M S B$ schedule. It follows that an institution that generates a capitalization function that approximates well the entire $M S B$ schedule would induce the first generation to make optimal choices.

The income tax institution performs poorly because, as shown in figure 2, it provides a poor approximation. By contrast, the capitalization function with land taxation 
approximates the $M S B$ schedule well in the case of reversible IPGs, and extremely poorly in the case of pure IPGs. For irreversible spillovers, the approximation is good when $\theta$ is close to one, but not when $\theta$ is large.

\subsection{Welfare}

A comparison of propositions 1 and 2 shows that a move from an income to a land tax base increases the efficiency of the economy. Thus, it is natural to ask if there are conditions under which the reform could be Pareto improving. The following result shows that this is never the case.

PROP 5: A move from an income to a land tax base increases the welfare of generation $\beta$ and decreases the welfare of generation $\alpha$ unless $D_{\max }=0$, and $\theta$ and $\lambda_{x}$ are sufficiently large. In that case, both institutions generate identical outcomes.

This result follows from the incidence properties of the two tax bases. Since the introduction of a land tax immediately capitalizes all future taxes into the price of land, the reform entails a massive redistribution from future to present generations. As a

result, the introduction of these institutions may require some form of compensation that is financed with non-land taxes. The compensations are likely to be large, but so are the efficiency gains.

\section{$5 \quad$ Extensions}

In this section we consider some complications that are important in the practical application of our results.

\subsection{Alternative Tax Bases}

A couple of problems arise in the implementation of a land tax base. First, although negative prices are a natural feature of the institution, they might be undesirable for political economy reasons. In particular, if land owners have strong political clout their taxes might be reduced when land prices drop sufficiently. This destroys their incentives to internalize the IG spillovers. The second concern is that land is not homogenous; some land plots are better than others. The government could tax all land equally, but this might be undesirable on an equity ground.

These two concerns motivate the extension developed in this section. We show that any other durable asset, or combinations of assets, that are inelastically supplied generate the same results. Examples include capital produced before the introduction of the institution, and luxury durable goods such as pre- $20^{t h}$ century art. 
Consider a simple extension of the model in which there are two assets traded at prices $p_{1}$ and $p_{2}$. There is an inelastic supply $L_{k}$ of each type. As before, agents are homogeneous. The preferences of generation $\beta$ now are given by $u(c)+v_{1}\left(l_{1}\right)+v_{2}\left(l_{2}\right)+$ $h(G) \cdot .^{13}$

Define a new tax base $L M$ which specifies the fraction of expenditures, $\sigma_{1}, \sigma_{2} \geq 0$, with $\sigma_{1}+\sigma_{2}=1$, that is paid with taxes on each asset. The taxes per-unit of asset at $t=1,2$ are given by

$$
\tau_{k}^{L M}(I, D)=\sigma_{k} \frac{I-D}{L_{k}} \text { and } \tau_{k}^{L M}(E, D)=\sigma_{k} \frac{E+D}{L_{k}} .
$$

The definition of equilibrium for this institution is a straightforward extension of definition $2 .{ }^{14}$

PROP 6: $L M$ generates full capitalization of tax spillovers, but no capitalization of benefit spillovers: for $k=1,2$, for all $s$,

$$
L_{k} p_{k}^{L M}(s)=L \pi_{k}(w)-\sigma_{k}\left(E^{L M}(s)+D\right) .
$$

This results is a straightforward extension of proposition 1(ii) and thus we only provide a sketch of the proof. As in Property 1, for any level $x>0$ of after tax wealth, there exists a unique pair of land-market clearing prices $\left(\pi_{1}(x), \pi_{2}(x)\right)$ such that $\lambda_{k}\left(\pi_{k}(x) \mid x\right)=\frac{L_{k}}{N}$ for $k=1,2$. It follows that, for all $s$,

$$
\begin{aligned}
p_{k}^{L M}(s) & =\pi_{k}(w)-\tau_{k}^{L M}\left(E^{L M}(s), D\right) \\
& =\pi_{k}(w)-\sigma_{k} \frac{\left(E^{L M}(s)+D\right)}{L}
\end{aligned}
$$

i.e., the price of each asset decreases exactly by the amount of the tax spillovers that it bears, and each additional unit of tax spillovers decreases the total value of both assets

${ }^{13} v_{1}(\cdot)$ and $v_{2}(\cdot)$ satisfy the same properties as $v(\cdot)$.

${ }^{14} \mathrm{An}$ equilibrium for $L M$ is given by $\left(p_{1}^{L M}(\cdot), p_{2}^{L M}(\cdot) E^{L M}(\cdot), I^{L M}, D^{L M}\right)$ satisfying:

(i) Political equilibrium in period 2: for all $s$

$$
E^{L M}(s)=\underset{E \geq 0}{\arg \max }\left[u\left(w-\sum_{k}\left(p_{k}^{L M}(s)+\tau_{k}^{L M}(E+D)\right) \frac{L_{k}}{N}\right)+h(\theta I+E)\right] ;
$$

(ii) Land market equilibrium: for all $s$ and for $k=1,2, p_{k}^{L M}(s)$ satisfies

$$
\frac{L_{k}}{N}=\lambda_{k}\left(p_{k}^{L M}(s)+\tau_{k}^{L M}\left(E^{L M}(s)+D\right) \mid w\right) ;
$$

(iii) Political equilibrium in period 1:

$$
\left(I^{L M}, D^{L M}\right) \in \underset{I \geq 0, D \leq D \max , I \leq N w+D}{\arg \max }\left[\sum_{k}\left(p_{k}^{L M}(\theta I, D)+\tau_{k}^{L M}(I, D)\right) \frac{L_{k}}{N}\right]
$$


by one exactly one unit. It follows, for the same reasons as before, that generation $\alpha$ fully internalizes the tax spillovers.

This result provides a solution to our two concerns. First, since the result holds for any shares $\sigma_{1}$ and $\sigma_{2}$, and it can be trivially extended to the case of $n$ assets, the government could address the problem of heterogenous land by dividing the land stock into several types and choosing an appropriate share for each type.

Next, proposition 6 implies that the price of asset $k$ is positive, in and out of equilibrium, as long as $\sigma_{k}<\frac{L_{k} \pi_{k}(w)}{G^{L M}+D_{\max }}$, where $G^{L M}=E^{L M}\left(0, D_{\max }\right)$ denotes the highest possible level of investment in IPGs by generation $\beta$. It follows that, by appropriately choosing the tax shares, the number of assets, and the debt ceiling, the institution can levy $\sum_{k} L_{k} \pi_{k}(w)$ units of revenue without generating negative prices. Thus, the government can address the political feasibility problem by adding assets to the tax base.

It is important to emphasize that the full capitalization results only hold for assets that are inelastically supplied. To see why, recall the intuition behind Proposition 3. With an inelastic asset and land taxation the total cost of land is unaffected by the policies of generation $\alpha$ and thus the demand for land remains fixed at $\frac{L}{N}$. This cannot be an equilibrium with an elastically supplied asset because, when prices increase in response to an additional unit of $s_{1}$, so does the supply of the asset. Thus, generation $\beta$ 's equilibrium consumption of the asset must increase with $s_{1}$. This can be the case only if each additional unit of $s_{1}$ increases land values by less than the full unit.

Our results can still be extended for the case of elastically supplied assets, such as property (as opposed to land), but they take the form of a limit result: as the elasticity of land supply goes to zero, the outcomes generated by the $L$ and $I$ institutions converge to those characterized in propositions 1 and 2. It follows that, for sufficiently inelastic assets, an asset tax base still outperforms an income tax base.

\subsection{Heterogenous Agents}

In the basic model we have assumed that agents are identical. A natural concern is that, since rich and poor voters pay different shares of the taxes and own a different amounts of land, they may respond differently to the capitalization driven incentives. In this section we explore the role of heterogeneity in our results.

Consider an extension of the model in which heterogeneity is introduced in the simplest possible way. Agent $i$ in generation $\alpha$ now receives an endowment of $w_{i}$ units of the private good and $l_{i}$ units of land. The aggregate endowments in both periods and the characteristics of generation $\beta$ remain unchanged.

It is straightforward to extend definitions 1 and 2 to this case. The only thing that changes are the political equilibrium conditions at $t=1$. Now, instead of solving the 
maximization problems in $(7)$ and $(10),\left(I^{k}, D^{k}\right)$ is required to be a Condorcet winner at $t=1$, and its existence is no longer trivially satisfied.

Consider, first, the effect of introducing heterogeneity in institution $L$. With land taxation, voter $i$ at $t=1$ prefers policy $(I, D)$ to policy $\left(I^{\prime}, D^{\prime}\right)$ if and only if

$$
\left(p^{L}(\theta I, D)-\frac{I-D}{L}\right) l_{i}>\left(p^{L}\left(\theta I^{\prime}, D^{\prime}\right)-\frac{I^{\prime}-D^{\prime}}{L}\right) l_{i} .
$$

Since this inequality is independent of $l_{i}$ and $w_{i}$, it follows that agents' policy preferences do not depend on their land holdings or wealth. Thus, Proposition 3 still holds.

Now consider institution $I$. The income tax base now specifies how different levels of expenditures map into the amount of taxes paid by each individual. Suppose, for simplicity, that agent $i$ always pays a fraction $\eta(i)$ of the taxes. Given this, agent $i$ optimal policy is given by

$$
\begin{aligned}
\left(I_{i}^{I}, D_{i}^{I}\right) & =\underset{I \geq 0, D \leq D_{\max }, I \leq N w+D}{\arg \max }\left[p^{I}(s) l_{i}-\eta(i)(I-D)\right] \\
& =\underset{I \geq 0, D \leq D_{\max }, I \leq N w+D}{\arg \max }\left[L p^{I}(s)-\frac{\eta(i)}{\frac{l_{i}}{L}}(I-D)\right],
\end{aligned}
$$

where $\frac{l_{i}}{L}$ denotes the share of land owned by agent $i$.

Now consider the role of the progressivity of the tax schedule on the policy preferences of a voter $i=m v$ who has the median income. With a sufficiently progressive tax system, $\eta(m v)<\frac{l m v}{L}$. In this case, since the median voter pays a small share of the taxes, he does not fully internalize the cost of public policy. Hence, he favors high levels of investment in IPGs, and is opposed to issuing debt even when there is only partial capitalization. ${ }^{15}$ By contrast, with a sufficiently regressive tax system, $\eta(m v)>\frac{l m v}{L}$. In this case the median voter opposes the production of IPGs and favors issuing debt.

We can conclude that, from an IG point of view, the attractiveness of an income tax base increases with its progressivity (as measured by the difference between $\eta(m v$ ) and $\left.\frac{l m v}{L}\right) .{ }^{16}$ The intuition is simple. The income tax base under-capitalizes tax spillovers. However, when the median voter pays a small share of the taxes, he also fails to internalize the full cost of the investment. This helps align his incentives with those of future generations. Unfortunately, since the under-capitalization of tax spillovers can be significant (recall that $\frac{\partial p^{I}}{\partial B} \rightarrow 0$ as $\lambda_{x} \rightarrow 0$ ), for plausible levels of progressivity the land tax base still provides more IG incentives than the income tax base.

${ }^{15}$ An additional unit of debt changes the median voter's payoff by $-L \frac{\partial p^{I}(s)}{\partial D}+\frac{\eta(m v)}{\frac{i m v}{L}}$, which can be negative even if $L \frac{\partial p^{I}(s)}{\partial D}>-1$. Similarly, an additional unit of IPGs changes his payoff by $L \frac{\partial p^{I}(s)}{\partial s_{1}}-\frac{\eta(m v)}{\frac{i m v}{L}}$, which can be positive even if $L \frac{\partial p^{I}(s)}{\partial s_{1}}<1$.

${ }^{16}$ This is an unconventional measure of progressivity. However, it correlates well with standard measures as long as land holdings increase with wealth. 


\subsection{Non-separable Preferences}

The basic results have been derived for the case of additively separable preferences, where the marginal rate of substitution between consumption and land, and thus the demand for land, are independent of $G$. This is a good assumption for IPGs such as pure R\&D, that are unrelated to land, but not for others, such as roads. In this section we show that for most (but not all) IPGs, our results extend to the case of nonseparabilities. To simplify the analysis, suppose that there is not debt $\left(D_{\max }=0\right)$.

We begin by characterizing the capitalization function for both tax bases. Consider first the case of land taxes. With non-additive preferences the land-market clearing condition becomes

$$
\frac{L}{N}=\lambda\left(p^{L}(s)+\frac{E^{L}(s)}{L} \mid w, G^{L}(s)\right) .
$$

The IFT then implies that

$$
L \frac{\partial p^{L}}{\partial s_{\mathbf{1}}}=-\frac{\partial E^{L}}{\partial s_{\mathbf{1}}}-\frac{\lambda_{G}}{\lambda_{p}} \frac{\partial G^{L}}{\partial s_{\mathbf{1}}}
$$

where $\frac{\partial E^{L}}{\partial s_{1}}$ denotes the sized of the tax spillovers generated by an additional unit of the IPG, and $\frac{\partial G^{L}}{\partial s_{1}}$ the size of the benefit spillover. As before, the tax spillover is fully capitalized. The main difference is that non-separabilities also make possible the capitalization of some of the benefit spillovers, which before were not capitalized at all. Since $\lambda_{p}<0$, the extent to which they are capitalized depends on the sign and magnitude of $\lambda_{G}$. Note, in particular, the capitalization of benefit spillovers is driven solely by the effect of the public good on the taste for land; the direct value of the spillovers for the next generation plays no role. Thus, a valuable benefit spillover such as more public parks and infrastructure can have a negative impact on land prices if it is a substitute for land $\left(\lambda_{G}>0\right)$.

A similar expression is easily derived for the income tax base. With non-additive preferences the land-market clearing condition becomes

$$
\frac{L}{N}=\lambda\left(p^{I}(s) \mid w-\frac{E^{I}(s)}{N}, G^{I}(s)\right) .
$$

Again, applying the IFT we get that

$$
L \frac{\partial p^{I}}{\partial s_{1}}=\frac{L}{N} \frac{\lambda_{x}}{\lambda_{p}} \frac{\partial E^{I}}{\partial s_{1}}-\frac{\lambda_{G}}{\lambda_{p}} \frac{\partial G^{I}}{\partial s_{1}} \frac{L}{N} .
$$

As before, the expression reduces to the case of non-separable preferences when $\lambda_{G} \approx 0$, and allows for the capitalization of benefit spillovers when $\lambda_{G} \neq 0$.

These arguments show that with non-separabilities both tax and benefit spillovers can be capitalized. The impact of this on IG incentives depends on the specific nature of the IPG. Many IPGs, such as pure R\&D, are orthogonal to land. In this case 
$\lambda_{G} \approx 0$ is the empirically relevant assumption, the capitalization of benefit spillovers is negligible, and our previous results remain unchanged.

For IPGs that are sufficiently strong complements to land, the addition of nonseparabilities shifts upwards the capitalization functions depicted in figures 2 and 3 . To be precise, the capitalization functions shift upwards only for values of $s_{1}$ at which an additional unit of the IPG generates a benefit spillovers. Thus, in the case of land taxes the capitalization function remains unchanged for $s_{1} \in\left[0, \bar{G}^{L}\right]$, and is positive otherwise, and in the case of income taxes the capitalization function increases throughout. It is straightforward to see that generation $\alpha$ 's incentives to invest, and the relative performance of the two tax bases, remains unchanged unless $\lambda_{G}$ and $\frac{\partial G^{k}}{\partial s_{1}}$ are sufficiently large.

Finally, for IPGs that are sufficiently strong substitutes for land, the addition of non-separabilites shifts the capitalization functions downwards. In the case of income taxation, the capitalization function shifts downwards throughout, further decreasing the ability of this institution to generate investment in IPGs. By contrast, with land

taxes the capitalization function remains unchanged up to $\bar{G}^{L}$, and becomes negative afterwards. This has no effect on the incentives of generation $\alpha$.

\subsection{Mobility}

The previous results have established the advantages of using a land tax base in a centralized institution. As we discussed in section 2, a related literature has shown that inter-jurisdictional competition also generates some capitalization of IG spillovers. This suggests a natural question: Do our results also hold in decentralized institutions? Or does the choice of the tax base only matter at the central level?

The analysis of this case is complicated and is done in a companion paper. Rangel and Conley (2002) compare the performance of four institutions: centralization and land taxation, centralization and income taxation, decentralization and land taxation, and decentralization and income taxation. The comparison shows that interjurisdictional competition and land taxation are complementary mechanisms. Decentralization generates full capitalization of benefit, but not of tax spillovers. Land taxation generates full capitalization of tax, but not of benefit spillovers. Thus, the choice of the tax base is also important at the state and local level.

\section{Conclusions: How to Protect Future Generations Using Tax Base Restrictions}

This paper has shown that the imposition of tax base restrictions can be used to protect future generations from expropriation and to improve the efficiency of intergenerational 
investment. The choice of the tax base matters because it affects the extent to which tax spillovers are capitalized: with a land-type tax base there is full capitalization, with an income tax base there is not.

Although our results have been developed in a highly stylized model, they suggest that a constitutional reform requiring the use of a multi-tier tax system could have a significant impact on intergenerational exchange. In this type of tax system, the government budget is divided into several well-defined tiers, and hard constraints are introduced into the tax base used to finance each tier. Our results suggest that there should be at least two tiers: (1) an IG tier, which includes programs that generate IG spillovers and debt; and (2) an intragenerational tier, which includes all other programs. Our results suggest that the IG tier should be financed exclusively with land taxes, but they do not impose any constraints on the tax base for the intragenerational tier. Thus, the system is compatible with other government objectives such as redistribution and corrective taxation.

This type of tax system introduces constraints on the budget process. Every fiscal year the government is free to choose how much to spend in each category, but is constrained on the type and amount of taxes that it can use to finance the different expenditures. Furthermore, there is a strong degree of separability among the tiers.

As we have shown, present generations have an incentive to relabel programs so that they can expropriate future generations. Thus, it is essential that the allocation of the budget items to tiers be well-defined and verifiable by a court, and that strong supermajorities be required to modify the rules of the tax system.

Admittedly, given the existing legal framework and the state of accounting and monitoring technology, it would impossible to create a constitutional framework that completely rules out the use of accounting gimmicks. This caveat notwithstanding, an institution that can guarantee that a sufficiently large fraction of IG programs is financed with a land-type tax base would still improve the incentives of present generations to care about the future.

Another difficulty in the practical implementation of a multi-tier tax system comes from the fact that some government objectives require the use of IG transfers, which as we have shown, are not possible with a land tax base. These activities include payas-you go social insurance programs, the use of debt to smooth business cycles, and IG risk-sharing. Thus, in order to protect future generations, the tax system needs to find a credible way of putting each one of these programs in a separate tier of the budget, and to introduce appropriate restrictions on how they are financed to insure that only acceptable IG transfers take place. In the case of business cycles, the constitution could require that a certain fraction of that type of debt be repaid whenever the economy is in an expansion. In the case of social insurance, the constitution could require that 
any changes in the level of benefits be financed with a specific type of payroll taxes.

The multi-tier system described here resembles the type of capital budget institutions that are common among the U.S. states in that it divides the budget into clearly specified categories and introduces some restrictions in the budget process. The difference between the two institutions resides on the nature of the restrictions. Here the government is free to choose expenditures and debt, but it is restricted on the type of taxes that it can use to finance it. By contrast, in standard capital budgeting institutions the government is constrained in its ability to spend and issue debt, but not in the choice of tax instruments.

We emphasize that, in order to generate the necessary IG incentives, a constitution needs to resort to a variety of mechanisms. The multi-tier system described here combines an appropriate choice of a tax base with some of the features of capital budgeting. The results in Rangel and Conley (2002) show that, for some types of IPGs, decentralization provides additional incentives to invest optimally. Other useful mechanisms are surely waiting to be discovered.

\section{References}

[1] Alt, James, and Robert Lowry (1994) "Divided Government, Fiscal Institutions, and Budget Deficits: Evidence from the States," American Political Science Review, 88:811-28.

[2] Altonji, L., F. Hayashi, and L. Kotlikoff (1992) "Is the Extended Family Altruistically Linked? Direct Tests Using Micro Data," American Economic Review, December, 1177-98.

[3] Altonji, L., F. Hayashi, and L. Kotlikoff (1997) "Parental Altruism and Inter Vivos Transfers: Theory and Evidence," Journal of Political Economy, December, 1121-66.

[4] Atkinson, Anthony, and Joseph Stiglitz (1980). Lectures in Public Economics. New York: McGraw Hill.

[5] Auerbach, Alan, and James Hines (2002) "Taxation and Economic Efficiency," in Handbook of Public Economics, volume 3, Alan Auerbach and Martin Feldstein (eds.), Amsterdam: Elsevier Science.

[6] Bohn, Henning, and Robert Inman (1995), "Constitutional Limits and Public Deficits: Evidence from the U.S. States," Carnegie-Rochester Conference Series on Public Policy. 
[7] Boldrin, Michele, and Ana Montes (1998) "Intergenerational Transfer Institutions: Public Education and Public Pensions," University of Minnesota, manuscript.

[8] Feldstein, Martin (1977) "The Surprising Incidence of a Tax on A Pure Rent: A New Answer to an Old Question," Journal of Political Economy, 85:349-60.

[9] Glaeser, Edward (1996) "The Incentive Effects of Property Taxes on Local Governments," Public Choice, 89:93-111.

[10] Kiewiet, Roderick, and Kristin Szakal (1996) "The Efficacy of Constitutional Restrictions on Borrowing, Taxing, and Spending: An Analysis of State Bonded Indebtedness, 1961-90," Journal of Law, Economics, and Organizations, 12:62-97.

[11] Kotlikoff, Larry, and Robert Rosenthal (1993) "Some Inefficiency Implications of Generatioal Politics and Exchange," Economics and Politics, 5, 27-42.

[12] Kotlikoff, Larry, and Larry Summers (1997) "Taxation Incidence," in Handbook of Public Economics, volume 2, Alan Auerbach and Martin Feldstein (eds.), Amsterdam: Elsevier Science.

[13] McKinnon, Ronald, and Thomas Nechyba (1997) "Competition in Federal Systems: The Role of Political and Financial Constraints," in The New Federalism: Can the States Be Trusted?, John Ferejohn and Barry Weingast (eds.), Hoover Press, 1-55.

[14] Oates, Wallace, and Robert Schwab (1988) "Economic Competition Among Jurisdictions: Efficiency Enhancing or Distortion Inducing?", Journal of Public Economics, 35:333-54.

[15] Oates, Wallace, and Robert Schwab (1996) "The Theory of Regulatory Federalism: The Case of Environmental Management", in The Economics of Environmental Regulation, Wallace Oates (ed.), Cheltenham, UK: Edward Elgar Publishing Limited.

[16] Poterba, James (1994) "State Responses to Fiscal Crises: The Effects of Budgetary Institutions and Politics," Journal of Political Economy, 102:799-821.

[17] Poterba, James (1995) "Capital Budgets, Borrowing Rules, and State Capital Spending”, Journal of Public Economics, 56(2): 165-87.

[18] Rangel, Antonio (2002) "Forward and Backward Intergenerational Goods: Why Is Social Security Good for the Environment," forthcoming in American Economic Review. 
[19] Rangel, Antonio, and John Conley (2002) "How to Protect Future Generations Using Federalism", Stanford manuscript.

[20] Report of the President's Commission on Capital Budgeting (1999). Washington, D.C.

[21] Skinner, Jonathan (1991) "Prospects for Agricultural Land Taxation in Developing Countries," The World Bank Economic Review, 5:493-511. 


\section{Appendix}

Proof of Property 1: The assumptions on preferences imply that: (1) $\lambda(p \mid x)$ is a strictly positive and continuously differentiable function, (2) for all $x>0, \lambda(p \mid x)>\frac{L}{N}$ for $p$ sufficiently low, and (iii) for all $x>0, \lambda(p \mid x) \rightarrow 0$ as $p \rightarrow \infty$. These three properties imply that there exists $p$ such that $\lambda(p \mid x)=\frac{L}{N}$. Uniqueness follows from the fact that at $\pi(x)$ the FOC $p u^{\prime}\left(x-p \frac{L}{N}\right)=v^{\prime}\left(\frac{L}{N}\right)$ must be satisfied, and the left hand side of this condition is increasing in $p$.

Proof of Properties 2 and 3: Since $\pi(x)$ is implicitly defined by $\lambda(\pi(x) \mid x)=\frac{L}{N}$, the Implicit Function Theorem (IFT) implies that $\frac{\partial \pi}{\partial x}=-\frac{\lambda_{x}}{\lambda_{p}}$, and Property 3 follows. Furthermore, since $\lambda(\pi(x) \mid x)$ is defined implicitly by $\pi(x) u^{\prime}(x-\pi(x) l)=v^{\prime}(l)$, the IFT implies that $\frac{\lambda_{p}}{\lambda_{x}}=-\lambda(\pi(x) \mid x)+\frac{u^{\prime}}{p u^{\prime \prime}}<-\lambda(\pi(x) \mid x)$. It follows that $\lambda(\pi(x) \mid x) \frac{\partial \pi}{\partial x}<1$. Since the assumptions on preferences imply that $\frac{\partial \pi}{\partial x}>0$, and by definition, $\lambda(\pi(x) \mid x)=$ $\frac{L}{N}$, Property 2 follows.

The following function is useful in the proofs below. Let

$$
G^{u}(s, p) \equiv \underset{G \geq 0}{\arg \max } u\left(w-p \frac{L}{N}-\frac{G-\theta I+D}{N}\right)+h(G)
$$

denote the level of IPGs that generation $\beta$ would choose at $t=2$ if the constraint $G \geq \theta I$ in (5) and (9) were not binding. The assumptions on preferences imply that $\frac{\partial G^{u}}{\partial w} \in(0, N)$. It follows that $\frac{\partial G^{u}}{\partial p}=-\frac{L}{N} \frac{\partial G^{u}}{\partial w} \in(-L, 0)$ and $\frac{\partial G^{u}}{\partial s_{1}}=-\frac{\partial G^{u}}{\partial D}=\frac{1}{N} \frac{\partial G^{u}}{\partial w} \in$ $(0,1)$. Furthermore, by the Inada conditions, $G^{u}(s, p)=0$ only if $p=\frac{N w+s-D}{L}$.

\section{Proof of Proposition 2:}

(Step 1) We show that for any state $s$ there exists a unique continuation equilibrium and characterize its basic properties.

For any $s$ the set of continuation equilibria is given by the intersection of the following loci in $(p, G)$ space. The first locus is given by the set of points $\left(p, G^{c}(s, p)\right)$, with

$$
G^{c}(s, p) \equiv \underset{G \geq s_{1}}{\arg \max }\left[u\left(w-p \frac{L}{N}-\frac{G-\theta I+D}{N}\right)+h(G)\right] .
$$

This is the set of points $(p, G)$ at which the conditions for political equilibrium are satisfied. As depicted in figure 4 , this locus satisfies the following properties: (1) $G^{c}(s, p)=\max \left\{G^{u}(s, p), s_{1}\right\} ;(2) G^{c}(s, \cdot)$ decreases in $p \in\left[0, \widetilde{p}\left(s_{1}\right)\right]$ and is flat otherwise (where $\widetilde{p}(0)=\frac{N w-D}{L}, \widetilde{p}(\cdot)$ is decreasing in $s_{1}$, and $\widetilde{p}\left(s_{1}\right)=0$ for all sufficiently large $\left.s_{1}\right)$; (3) $\frac{\partial G^{c}}{\partial p}=-\frac{L}{N} \frac{\partial G^{u}}{\partial w} \in(-L, 0)$ if $p<\widetilde{p}\left(s_{1}\right)$; and (4) the locus $G^{c}(s, \cdot)$ shifts upwards with $s_{1}$, and downwards with $D$. 
The second locus is given by the set of points $\left(\pi\left(w-\frac{D+\max \{G-\theta I, 0\}}{N}\right), G\right)$ that satisfy the conditions for a land market equilibrium. As shown in figure 4, this locus satisfies the following properties: (1) it crosses the horizontal axis at a price $\hat{p} \in\left(0, \frac{N w-D}{L}\right)$ and then increases vertically up to the point $\left(\hat{p}, s_{1}\right) ;(2)$ it decreases for $p \in[0, \hat{p}]$ and, since $\frac{\partial \pi}{\partial G}=-\frac{1}{N} \frac{\partial \pi}{\partial x} \in\left(-\frac{1}{L}, 0\right)$, Property 2 implies that the slope is between $-\infty$ and $-L ;(3)$ it shifts to the left as $D$ increases.

The properties of the two loci imply that: (1) they intersect exactly once, (2) the price at the intersection is less than $\frac{N w-D}{L}$ and thus $c^{I}(s)>0$, (3) for all $D$ there exists $\bar{G}^{I}(D)$ such that $G\left(s_{1}, D\right)=s_{1}$ if $s_{1} \geq \bar{G}^{I}(D)$, and $G\left(s_{1}, D\right)>s_{1}$ otherwise, and (4) $\bar{G}^{I}(D)$ decreases with $D$.

(Step 2) Now we show how changes in $s$ affect the continuation equilibrium. There are two possible cases:

Case 1: $s_{1}<\bar{G}^{I}(D)$. In this case $\left(p^{I}(s), G^{I}(s)\right)$ is given by the unique solution to the following system of equations:

$$
p=\pi\left(w-\frac{G-\theta I+D}{N}\right) \text { and } N h^{\prime}(G)=u^{\prime}\left(w-p \frac{L}{N}-\frac{G-\theta I+D}{N}\right) .
$$

The IFT implies that $\left(p^{I}(\cdot), G^{I}(\cdot)\right)$ is $C^{\mathbf{1}}$ differentiable and that

$$
\begin{gathered}
\frac{\partial p^{I}}{\partial s_{1}}=-\frac{\partial p^{I}}{\partial D}=\frac{1}{L} \frac{-\frac{L}{N} \frac{\partial \pi}{\partial x} N h^{\prime \prime}}{-N h^{\prime \prime}+\frac{U^{\prime \prime}}{N}\left(\frac{L}{N} \frac{\partial \pi}{\partial x}-1\right)} \text { and } \\
\frac{\partial G^{I}}{\partial s_{1}}=-\frac{\partial G^{I}}{\partial D}=\frac{\frac{U^{\prime \prime}}{N}\left(\frac{L}{N} \frac{\partial \pi}{\partial x}-1\right)}{\frac{U^{\prime \prime}}{N}\left(\frac{L}{N} \frac{\partial \pi}{\partial x}-1\right)-N h^{\prime \prime}} .
\end{gathered}
$$

Property 2 then implies that $\frac{\partial p^{I}}{\partial s_{1}}, \frac{\partial G^{I}}{\partial s_{1}} \in(0,1)$.

Case $2: s_{1} \geq \bar{G}^{I}(D)$. In this case $\left(p^{I}(s), G^{I}(s)\right)=\left(\pi\left(w-\frac{D}{N}\right), s_{1}\right)$ and thus $\frac{\partial p^{I}}{\partial s_{1}}=0$ and $\frac{\partial p^{I}}{\partial D}=-\frac{1}{N} \frac{\partial \pi}{\partial x}$. Property 2 implies that $L \frac{\partial p^{I}}{\partial D} \in(-1,0)$. The properties of $E^{I}(\cdot)$ then follow from the fact that $E^{I}(s)=G^{I}(s)-s_{1}$.

(Step 3) Parts (iii) and (iv) of the proposition follow directly from the properties of the capitalization function and the fact that, by Proposition $1, \frac{\partial p^{I}}{\partial s_{1}} \rightarrow 0$ as $\lambda_{x} \rightarrow 0$.

(Step 4) Finally we show that $G^{I}$ is inefficient. There are two cases. If $E^{I}\left(\theta I^{I}, D_{\max }\right)>$ 0 , (5) implies that the FOC $u^{\prime}\left(c^{I}(s)\right)=N h^{\prime}\left(G^{I}\right)$ is satisfied. If $E^{I}\left(\theta I^{I}, D_{\max }\right)=0$, the arguments in step 1 imply that $G^{I}=\bar{G}^{I}\left(D_{\max }\right)$, and as a result the same FOC must be satisfied. In either case generation $\beta$ 's aggregate willingness to pay for an additional unit of IPGs is 1 . This exceeds $\frac{1}{\theta}$, the marginal cost of producing an additional unit of IPGs. Since generation $\beta$ is at an interior allocation, it follows that a Pareto improvement is possible.

\section{Proof of Proposition 3:}


(Step 1) We show that for every state $s$ there exists at most one continuation equilibrium. As in the previous proof, the continuation equilibria is given by the intersection of the following loci in $(p, G)$ space. The first locus is given by the set of points $\left(p, G^{c}(s, p)\right)$ that satisfy the conditions for political equilibrium. The properties of this locus are described in step 1 of the previous proof.

The second locus is given by the set of points $\left(p^{\prime}(G, s), G\right)$ that satisfy the land market clearing conditions. Property 1 implies that $p^{\prime}(G, s)=\pi(w)-\frac{D+\max \{G-\theta I, 0\}}{L}$. It follows that the locus satisfies the following properties: (1) it crosses the horizontal axis at a price $\hat{p}=\pi(w)-\frac{D}{L}$ and then increases vertically up to the point $\left(\hat{p}, s_{1}\right),(2)$ for $p \in[0, \hat{p}]$ it decreases linearly with slope $-L$; and (3) increases in $D$ shift the locus to the left.

The properties of the two loci imply that they can intersect at most once.

(Step 2) By step 1, to show that $E^{L}(s)=\max \left\{\bar{G}^{L}-\theta I, 0\right\}$ and $p^{L}(s)=\pi(w)-$ $\frac{\left(D+\max \left\{\bar{G}^{L}-\theta I, 0\right\}\right)}{L}$ is the unique continuation equilibrium it suffices to check that it satisfies conditions (8) and (9).

(Step 3) Parts (iii) and (iv) follow directly from the properties of the capitalization function. The argument for why $G^{L}$ is Pareto inefficient is analogous to the one in step 4 in the previous proof and thus is omitted.

(Step 4) Finally, consider the claim in part (v). Property 1 implies that $p^{I}\left(\bar{G}^{I}(0), 0\right)=$ $\pi(w)=p^{L}\left(\bar{G}^{L}, 0\right)$ since generation $\beta$ pays not taxes in those states. Furthermore, since $\bar{G}^{L}=G^{u}\left(\left(\bar{G}^{L}, 0\right), p^{L}\left(\bar{G}^{L}, 0\right)\right)$ and $\bar{G}^{I}(0)=G^{u}\left(\left(\bar{G}^{I}(0), 0\right), p^{I}\left(\bar{G}^{I}, 0\right)\right)$, it follows that $\bar{G}^{I}(0)=\bar{G}^{L}$.

Parts (i) and (iv) of Proposition 2 imply that $G^{I} \leq \bar{G}^{I}$ ( $\left.D_{\max }\right)$, with strict inequality if $\theta$ or $\lambda_{x}$ are small. Step 1 in the previous proof shows that $\bar{G}^{I}(D)$ is strictly decreasing in $D$. Putting all of the inequalities together we get that

$$
G^{I} \leq \bar{G}^{I}\left(D_{\max }\right) \leq \bar{G}^{I}(0)=\bar{G}^{L}=G^{L},
$$

with strict inequality if $\theta$ or $\lambda_{x}$ are small or if $D_{\max }>0$.

\section{Proof of Proposition 4:}

The proof of the case or pure IPGs is given in the text. Consider the case of reversible IPGs. The following steps characterize the unique equilibrium allocations generated by the two institutions. Since the arguments are similar to those in the proofs of propositions 2 and 3 we only provide a sketch of the proof.

(Step 1) Consider the case of a land tax base. An argument analogous to the one in step 1 of the previous proof shows that for every $s$ there exists at most one continuation 
equilibrium. It is then straightforward to check that $E^{L}(s)=\widetilde{G}^{L}-s_{1}$ and $p^{L}(s)=$ $\pi(w)-\frac{D+E^{L}(s)}{L}$ satisfy the conditions for land market clearing and political equilibrium in period 2. It follows that $L \frac{\partial p^{L}}{\partial s_{1}}=1$ for all $s_{1}$ and that $L \frac{\partial p^{L}}{\partial D}=-1$. Given this, generation $\alpha$ 's best response is to choose $\left(D^{I}, I^{I}\right)=(0, N w)$, which is Pareto optimal.

(Step 2) Consider the case of an income tax base. The arguments in steps 1 and 2 in the proof of Proposition 2 go through virtually unmodified. In fact, the arguments are simpler since we do not have to worry about corner solutions: the outcome of the election of at $t=2$ is given by $G^{u}(s, p)$. It follows that generation $\alpha$ sets $I^{I}=0$ unless $\theta$ and $\lambda_{x}$ are sufficiently large.

\section{Proof of Proposition 5:}

For $k=L, I$, and any state $s$, let $W^{k}(s)$ denote the wealth of generation $\alpha$ and $U^{k}(s)$ denote the payoff of generation $\beta . W^{k}=W^{k}\left(\theta I^{k}, D^{k}\right)$ and $U^{k}=U^{k}\left(\theta I^{k}, D^{k}\right)$ denote the payoff at the outcomes generated by the institutions.

(Step 1) Proposition 3 implies that $W^{k}=L \pi(w)-\frac{\bar{G}^{L}}{\theta}$ and $U^{k}=u(w-L \pi(w))+$ $v\left(\frac{L}{N}\right)+h\left(\bar{G}^{L}\right)$.

(Step 2) As was shown in step 4 of the proof for Proposition $3, \bar{G}^{I}(0)=\bar{G}^{L}$ and $p^{I}\left(\bar{G}^{L}, 0\right)=p^{L}\left(\bar{G}^{L}, 0\right)=\pi(w)$. It follows that with an income tax base generation $\alpha$ can replicate the outcome of $L$ by choosing $\left(I^{I}, D^{I}\right)=\left(\frac{\bar{G}^{L}}{\theta}, 0\right)$. Revealed preference then implies that $W^{I} \geq W^{I}\left(\bar{G}^{L}, 0\right)=W^{L}$, with strict inequality if $D_{\max }>0$ or $I^{I} \neq \frac{\bar{G}^{L}}{\theta}$.

(Step 3) $U^{k}(s)=u\left(w-\frac{L}{N} p^{I}(s)-\frac{E^{I}(s)+D}{N}\right)+v\left(\frac{L}{N}\right)+h\left(s_{1}+E^{I}(s)\right)$ implies that

$$
\frac{\partial U^{k}(s)}{\partial s_{1}}=-u^{\prime} \cdot\left[\frac{L}{N} \frac{\partial p^{I}}{\partial s_{1}}+\frac{1}{N} \frac{\partial E^{I}}{\partial s_{1}}\right]+h^{\prime} \cdot\left(\frac{\partial E^{I}}{\partial s_{1}}+1\right)=\frac{\partial E^{I}}{\partial s_{1}}\left(h^{\prime}-\frac{u^{\prime}}{N}\right)+h^{\prime}-u^{\prime} \frac{L}{N} \frac{\partial p}{\partial s_{1}} .
$$

To sign this derivative note that there are two possible cases. When $E^{I}(s)>0$ the FOC $h^{\prime}=\frac{u^{\prime}}{N}$ holds and thus $\frac{\partial U^{k}(s)}{\partial s_{1}}>0$. When $E^{I}(s)=0, \frac{\partial p^{I}}{\partial s_{1}}=0$ and $h^{\prime}<\frac{u^{\prime}}{N}$, which also imply that the derivative is positive. This implies that $U^{I} \leq U^{I}\left(\bar{G}^{I}\left(D_{\max }\right), D_{\max }\right)$, with strict inequality if $I^{I}<\bar{G}^{I}\left(D_{\max }\right)$.

To conclude the proof note that $D>0$ implies that

$$
U^{I}\left(\bar{G}^{I}(D), D\right)=u\left(w-\frac{L}{N} p^{I}(s)-\frac{D}{N}\right)+v\left(\frac{L}{N}\right)+h\left(\bar{G}^{I}(D)\right)<U^{L}
$$

since $\bar{G}^{I}(D)<\bar{G}^{L}$ and, by properties 1 and 2 ,

$$
\frac{L}{N} p^{I}\left(\bar{G}^{I}(D), D\right)-\frac{D}{N}=\frac{L}{N} \pi\left(w-\frac{D}{N}\right)-\frac{D}{N}>\frac{L}{N} \pi(w) .
$$




\begin{tabular}{|c|c|c|c|c|c|}
\hline $\begin{array}{l}\text { generation } \alpha \\
\text { born }\end{array}$ & $\begin{array}{l}\text { politics: } \\
\text { choose }(I, D)\end{array}$ & $\begin{array}{l}\text { generation } \beta \\
\text { born }\end{array}$ & $\begin{array}{l}\text { land market, } \\
\text { generation } \alpha \\
\text { consumes } \\
\text { and dies }\end{array}$ & $\begin{array}{l}\text { politics: } \\
\text { choose } E\end{array}$ & $\begin{array}{l}\text { generation } \beta \\
\text { consumes } \\
\text { and dies }\end{array}$ \\
\hline
\end{tabular}

Figure 1: Timing of the model 

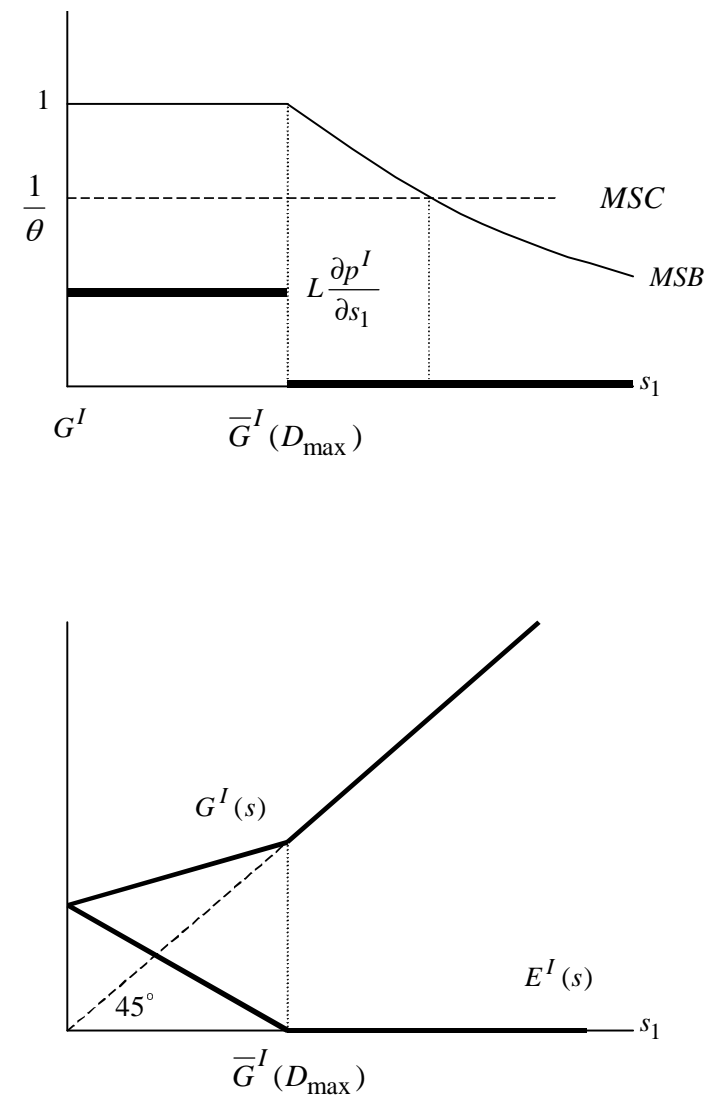

Figure 2: Equilibrium with an income tax base. Top: capitalization function. Bottom: policy response function. 

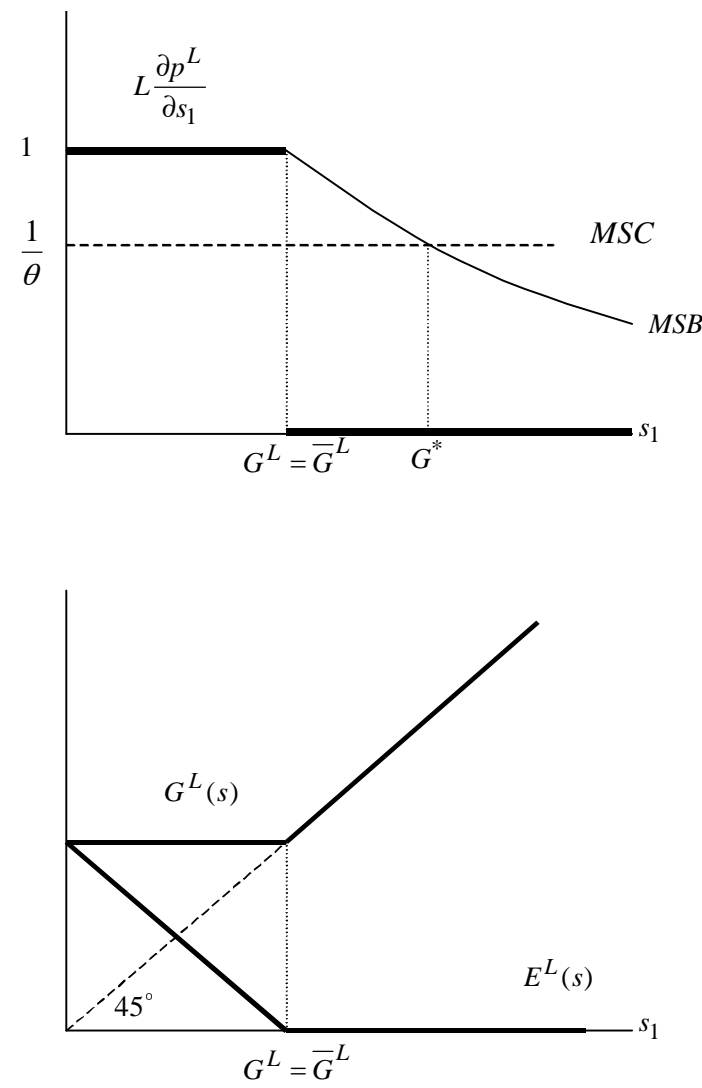

Figure 3: Equilibrium with a land tax base. Top: capitalization function. Bottom: policy response function. 


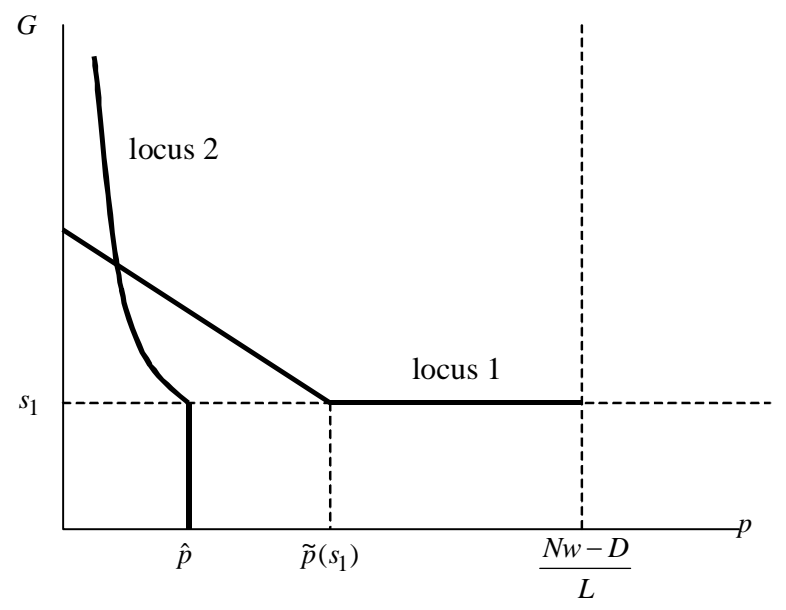

Figure 4: Proof of Proposition 2 - necessary and sufficient conditions for a continuation equilibrium 